\title{
Management of the stalked barnacle (Pollicipes pollicipes) fishery in the Berlengas Nature Reserve (Portugal): evaluation of bag and size limit regulation measures
}

\author{
DAVID JACINTO ${ }^{1,2}$, TERESA CRUZ ${ }^{1,2,3}$, TERESA SILVA ${ }^{1,2}$ and JOÃO J. CASTRO ${ }^{1,2,3}$ \\ ${ }^{1}$ Laboratório de Ciências do Mar, Universidade de Évora, 7520-903 Sines, Portugal. E-mail: djacinto@ uevora.pt \\ ${ }^{2}$ Centro de Oceanografia, Faculdade de Ciências da Universidade de Lisboa, Lisboa, Portugal. \\ ${ }^{3}$ Departamento de Biologia, Universidade de Évora, Évora, Portugal.
}

SUMMARY: The stalked barnacle Pollicipes pollicipes (Gmelin, 1790) is an important shellfish resource in Portugal. Due to the social-economic importance of barnacle harvesting, a management plan aimed at achieving a controlled and sustainable activity (including temporal and spatial closures, rotational harvesting, a limited number of harvesting licenses, bag and size limits for catches and catch reporting) was implemented in 2000 at the Berlengas Nature Reserve (RNB) in central Portugal. We evaluated the bag and size limits imposed by the management plan, performing observations on harvesting activity and asking licensed harvesters and RNB staff about these measures. Both inquiries and observations suggest that licensed harvesters are not following the bag and size limits imposed. Mean amounts captured in RNB varied from 14 to $24 \mathrm{~kg}$ per harvester/day, but $25 \%$ of the observations corresponded to higher catches per individual than the total amount allowed (20 $\mathrm{kg}$ ). Only half of the sampled amounts (taken in autumn 2005 and 2006) were in agreement with the size limit regulation and $50 \%$ of the total biomass comprised individuals of maximal rostro-carinal length $(\mathrm{RC}) \geq 25 \mathrm{~mm}$. For most harvesters, size limit is the most difficult management rule to fulfil. Both harvesters and RNB staff agree that surveillance is scarce and is a major problem of this fishing activity. In order to achieve a more sustainable use of this resource, we propose the implementation of a more effective surveillance and monitoring plan, the definition of a unique landing site, the maintenance of the bag limit ( $20 \mathrm{~kg}$ ) and a reduction of the size limit (50\% of total biomass comprising individuals $\geq 22 \mathrm{~mm} \mathrm{RC}$ ).

Keywords: stalked barnacles, Pollicipes, fishery, management, marine reserve, Portugal.

RESUMEN: Gestión de la explotación de percebe (Pollicipes pollicipes) en la Reserva Natural de Berlengas (PorTUGal): eVAlUación Del tOPE DE CAPTURAS y talla mínima. - El percebe Pollicipes pollicipes (Gmelin, 1790) es un recurso importante en Portugal. Debido a la importancia socioeconómica de la recolección de percebes y con objeto de alcanzar una actividad controlada y sostenible, se implementó en 2000 en la Reserva Natural de Berlengas (RNB; centro de Portugal) un plan de gestión para regular esta actividad (incluyendo el cierre temporal y espacial, rotación de la explotación, número limitado de licencias, topes de captura individual y talla mínima). Hemos evaluado los topes de captura y la talla mínima impuestos por el plan de gestión, realizando observaciones sobre la actividad de recolección y realizando encuestas a perceberos y personal de la RNB sobre tales medidas. Los perceberos no están siguiendo los topes de captura y los límites de tamaño establecidos. Las cantidades medias capturadas en la RNB han variado de 14 a $24 \mathrm{~kg}$ por mariscador/día, pero el $25 \%$ de las observaciones corresponden a las capturas por persona superior al importe total permitido (20 kg). Sólo la mitad de las muestras (tomadas en el otoño de 2005 y 2006) se mostró de acuerdo con el reglamento de límite de tamaño (50\% de la biomasa total que incluye percebes de un máximo de longitud rostro-carinal $\mathrm{RC} \geq 25 \mathrm{~mm}$ ). Para la mayoría de los mariscadores, el límite de tamaño es la norma de gestión más difícil de cumplir. Con el fin de alcanzar un uso más sostenible de este recurso, se propone la implantación de un plan de monitorización y vigilancia más eficaz, la definición de un único lugar de descarga, el mantenimiento del tope de captura individual $(20 \mathrm{~kg})$ y la reducción de la regulación de talla mínima $(50 \%$ de la biomasa total compuesto por individuos $\geq 22 \mathrm{~mm} \mathrm{RC}$ ).

Palabras clave: percebes, Pollicipes, pescas, gestión, reservas marinas, Portugal. 


\section{INTRODUCTION}

The stalked barnacle (Pollicipes pollicipes Gmelin, 1790) lives attached to rocks on very exposed shores (Borja et al., 2006a), forming dense aggregations of different-sized individuals in the intertidal and shallow subtidal zone along the northeast Atlantic coast from $48^{\circ}$ to $14^{\circ} \mathrm{N}$ (Barnes, 1996). During the last few decades, $P$. pollicipes has been highly prized as food and heavily exploited along the Portuguese and Spanish coasts, where there is strong market demand for this resource (Cruz, 2000; Molares and Freire, 2003; Bald et al., 2006; Borja et al., 2006b; Jesus, 2006).

Along the Portuguese coast, intense harvesting of $P$. pollicipes occurs wherever it is abundant. Most of the catches are sold directly to intermediates or to the final consumer and official fishery data are scarce and hardly reflect the harvesting pressure applied to the local barnacle populations (Cruz, 2000; Castro, 2004; Jesus, 2006). Despite its commercial interest, professional barnacle harvesting along the Portuguese coast is not subject to specific regulations, except in the Berlengas Nature Reserve (since 2000) and in another protected area, the Natural Park of Sudoeste Alentejano and Costa Vicentina (since 2006).

The Berlengas Nature Reserve (Reserva Natural das Berlengas, RNB) is situated approximately 6 miles off Cabo Carvoeiro (central Portugal, Fig. 1). It was created in 1981 due to its importance as an insular ecosystem, its high marine biological value, its botanical interest and importance to marine avifauna, and the presence of interesting archaeological features. At that time, the protected land area included the main island (Berlenga), a small set of islands (Estelas), and a marine protected area surrounding them (defined by the 30 m bathymetric; Fig. 1). From 1989 to 1998, barnacle harvesting was forbidden in the protected area, but barnacles were nevertheless exploited and barnacle harvesting control was ineffective (Cruz, 2000).

In 1998 the reserve was reclassified as an area limited by meridians and parallels $\left(39^{\circ} 24^{\prime}\right.$ to $39^{\circ} 30^{\prime} \mathrm{N}$ and $09^{\circ} 28^{\prime}$ to $09^{\circ} 34^{\prime} \mathrm{W}$ ) that included the Berlenga, Estelas and Farilhões islands and a larger marine protected area (Fig. 1). Between 1998 and 2000 barnacle harvesting in the RNB was totally forbidden but illegal barnacle harvesting in the RNB never ceased (Cruz, 2000).

Due to the socio-economic importance of barnacle harvesting in this region, a management plan for barnacle harvesting in the RNB was implemented in 2000 with the aim of achieving a more controlled and sustainable activity. This plan includes temporal and spatial closures, rotational harvesting, a limited number of harvesting licences, bag and size limits for the catches and catch reporting (Table 1). However, there were no a priori socio-economic studies on $P$. pollicipes harvesting in the RNB and on the in situ biology of this resource to support these regulation measures. From 2000 to 2004, there were no studies or monitoring programmes to evaluate the management plan and the sustainability of this activity in the protected area. A research project on this fishery in the RNB was carried out between 2005 and 2008 (Cruz et al., 2008). One of the goals of this project was to evaluate the effectiveness of several regulation measures included in the management plan, such as the bag and size-limit rules (the objective of the present work), the quality of logbook data (Jacinto et al., 2010) and the temporal and spatial closures. From 2005 to 2007, we made harvesting observations and asked licensed harvesters and the RNB staff about the bag and size-limit rules. On the basis of these observations and opinions, we identified the main problems and proposed solutions that may increase control of such measures and help to achieve a more effective and sustainable use of $P$. pollicipes in the RNB.

\section{MATERIALS AND METHODS}

\section{Harvesting observations}

In 2005 and 2006, 45 individual annual licenses for barnacle harvesting were issued (to the same persons in both years) by the Portuguese fisheries authority (Direcção-Geral das Pescas e Aquicultura) in agreement with the RNB. These men normally work in small groups (from 1 to 8 licensed harvesters) divided by 13 small rigid inflatable or fibreglass boats with powerful engines (12 boats in 2006) based at the port of Peniche (42 harvesters, 10-11 boats) and at Baleal ( 3 harvesters, 2 boats), a small bay north of Peniche (Fig. 1).

A total of 51 days of observation on barnacle harvesting activity was carried out between June 2005 and December 2006 (24 in 2005 and 27 in 2006). Most observations were made at the Port of Peniche, where most of the catch is landed $(n=21$ in $2005 ; n=26$ in 2006), and a few at the RNB by accompanying the

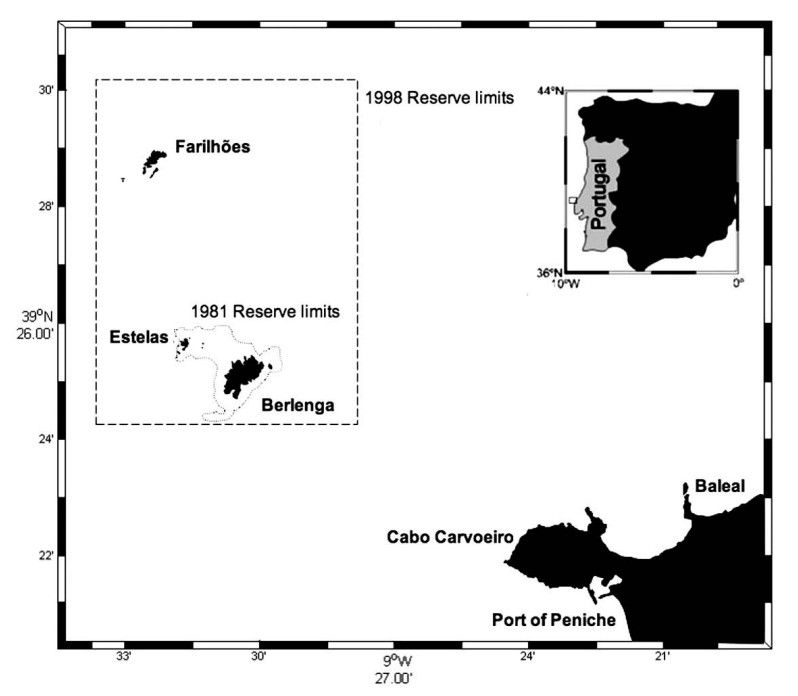

FIG. 1. - Location of the Berlengas Nature Reserve relative to Cabo Carvoeiro and mainland Portugal (inset). The reserve limits (1981 and 1998) are shown as dotted lines in the figure. 
TABLE 1. - Summary of the management plan for Pollicipes pollicipes harvesting enforced since 2000 in the Berlengas Nature Reserve (RNB).

\begin{tabular}{|c|c|}
\hline Temporal closures & $\begin{array}{l}\text { Harvesting is not allowed during August and September, on Mondays, Fridays, weekends and holidays, and at } \\
\text { night. }\end{array}$ \\
\hline Spatial closures & Permanent no-take zones (zone C) were defined in the RNB area. \\
\hline Rotational harvest & Harvesting is spatially limited to the intertidal area of zone A during odd years and of zone B during even years. \\
\hline Bag limit & A maximum amount of $20 \mathrm{~kg} \mathrm{day}^{-1}$ per harvester (without sorting) is allowed. \\
\hline Size limit & At least $50 \%$ of the harvest volume must contain individual barnacles with a rostro-carinal length $>25 \mathrm{~mm}$. \\
\hline Technique & $\begin{array}{l}\text { Harvesters are allowed to exploit intertidal barnacle populations during low tide or high tide (by free diving) with } \\
\text { the aid of a spatula. }\end{array}$ \\
\hline Harvesting licenses & $\begin{array}{l}\text { A defined number of licenses are issued yearly (e.g. } 45 \text { licenses in 2006). Criteria for license issuing are also } \\
\text { defined yearly. }\end{array}$ \\
\hline Catch reporting & $\begin{array}{l}\text { Each harvester must present a semestral log-book to the RNB, with data on harvested amounts, harvesting dates, } \\
\text { exploited areas and destination of the catch. }\end{array}$ \\
\hline
\end{tabular}

harvesters in their boats to the harvesting sites $(n=3$ in 2005; $n=1$ in 2006). All observations were pooled for data analysis, as there was no evidence, according to our observations, inquiries and informal conversations with the harvesters, of barnacle sorting between the harvesting sites and the Port of Peniche.

Whenever possible, we counted the number of boats going to, coming from, or participating in the harvest $(n=51)$ and the number of harvesters per boat $(n=35)$. We randomly weighed the total harvest amounts per boat $(n=69)$ and per capita (dividing the total amount per boat by the number of harvesters per boat, $n=287$ ). Harvest amounts were weighed using a portable spring balance scale (precision of $\pm 0.05 \mathrm{~kg}$ ).

In order to characterize the size structure of harvested barnacles and to determine whether the management regulation concerning size limit was being fulfilled, we collected ten sub-samples of barnacles $(269.4 \pm 93.90 \mathrm{~g}$, mean \pm standard deviation) from ten individual harvest amounts landed at the Port of Peniche in the autumn of 2005 and 2006 (5 sampling dates and 8 sampling boats). We measured the individual size as the maximal rostrocarinal length $(\mathrm{RC})$ at a precision of $\pm 0.05 \mathrm{~mm}$ and fresh weight per size class at a precision of $\pm 0.05 \mathrm{~g}$. We considered five size classes based on RC length (mm): ]5, 12.5], ]12.5, 16.5], ]16.5, 20.5], ]20.5, 24.5[ and $\geq 24.5$. These size classes were defined on the basis of their contribution to the reproductive status of the population (according to Cruz and Araújo, 1999) and estimated age (based on Cruz et al., 2010), and on their commercial relevance (personal observations): the first class corresponded to juveniles, the second to less than 1-year-old adults with low reproductive input, the third to fully matured individuals ( $<1$ year old) with low commercial interest, the fourth to adults (mostly $\geq 1$ year old) with commercial interest, and the fifth class to highly prized older individuals. The size limit rule of the management plan states that at least $50 \%$ of the harvest volume must contain individual barnacles with a $\mathrm{RC} \geq 25 \mathrm{~mm}$ (considered in the present paper as the fifth class.).

\section{Enquiries}

\section{Harvesters}

Licensed harvesters (84\% of the target population of 45 fishermen) were individually interviewed between December 2005 and February 2007. A set of closed and open questions were asked in order to make a social characterization of the harvesters' population (e.g. age, residence area, years in this activity, importance of barnacle harvesting for total income) and to gather opinions on the bag and size limits imposed by the management plan (e.g. knowledge of the rules, sense of transgression, rule agreement). Additionally, a set of 6 reference barnacles with different RC lengths (A-14 mm, B-17 mm, C-20.1 mm, D-22 mm, E-25.3 $\mathrm{mm}$ and F-29.6 mm) was shown to each harvester and their opinion on the size (very bad to excellent) and intention to harvest (yes versus no) of such barnacles was registered.

\section{RNB nature guards}

All the nature guards of RNB ( $n=5)$ were individually interviewed between October 2006 and January 2007. A set of closed and open questions were asked to gather opinions on the management plan, surveillance and control of barnacle harvesting activity in the RNB.

\section{RESULTS}

\section{Harvesting observations}

The number of boats observed per day varied between 0 and $10(3.9 \pm 3.36$, mean $\pm S D, n=51)$, and the number of licensed harvesters observed per day varied between 0 and $42(12.0 \pm 11.5$, mean $\pm S D, n=35)$.

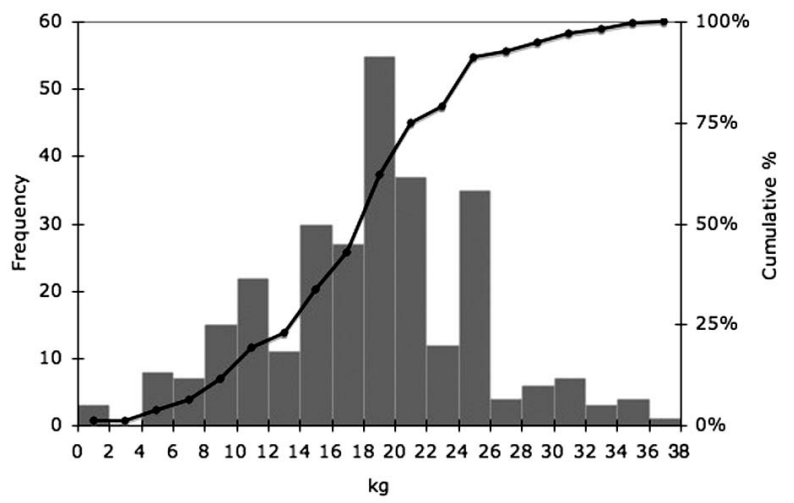

FIG. 2. - Fishery of $P$. pollicipes in the RNB: frequency and cumulative frequency distribution of the average amount of barnacles $(2 \mathrm{~kg}$ size classes) landed per harvester per day $(n=287)$. 


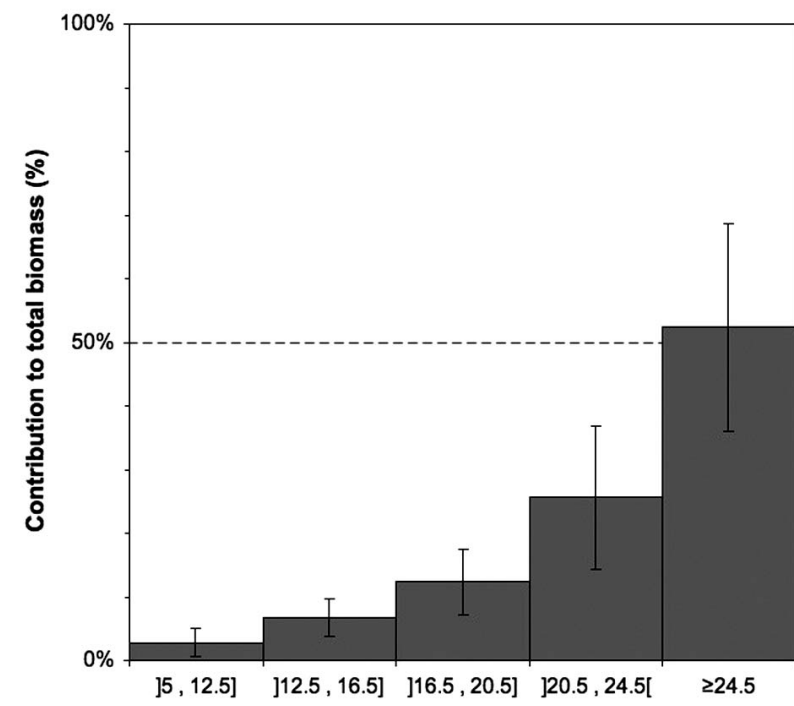

FIG. 3. - Fishery of $P$. pollicipes at RNB: relative contribution (mean \pm SD) to total biomass (fresh weight) of each size class (RC, $\mathrm{mm})$ in individual sub-sampled harvest amounts $(\mathrm{n}=10)$ in autumn 2005 and 2006.

Mean $( \pm \mathrm{SD})$ total harvest amount per harvester was $16.7 \pm 7.06 \mathrm{~kg} \mathrm{day}^{-1}$ (amounts landed by 69 boats and corresponding to 287 individual harvest amounts). Frequency distribution of the amounts landed per harvester (Fig. 2) show that $74.9 \%$ of the catches per individual were less than or equal to $20 \mathrm{~kg}$ (the bag limit).

The relative contribution of each size class to the total biomass of the barnacles sampled in autumn 2005 and 2006 is presented in Figure 3. On average, the $>24.5 \mathrm{~mm}$ dimensional class volume was $52.4 \pm 16.3 \%$ $($ mean \pm SD) of the total sample volume.

\section{Interviews}

\section{Harvesters}

\section{Social characterization}

All licensed harvesters working at the RNB were men aged between 28 and 65 years, and most lived less than 30 $\mathrm{km}$ from the port of Peniche. The majority of them (89\%) had been working as barnacle harvesters for more than 10 years, and this activity was well established in their family (65\% had one or more family members working as barnacle harvesters). Most of them (66\%) claimed that barnacle harvesting was their main professional activity, although $82 \%$ had other sources of income (mostly related to other fisheries and commerce). For $97 \%$ of the interviewees, barnacle harvesting was an important or very important source of their family income.

The harvesting management plan at the RNB: bag and size limits

About $87 \%$ of the harvesters interviewed had been working as licensed harvesters at the RNB since 2000 (the year of implementation of the management plan) and all claimed to know the adopted measures. However, there was a generalized opinion (87\%) that the harvesters did not comply with the regulation. Regarding the bag and size limit regulations, all harvesters were aware of the $20 \mathrm{~kg}$ bag limit, but only $66 \%$ knew that $25 \mathrm{~mm}$ (RC length) was the size limit that at least half of the catch biomass must contain (21\% were unaware of the exact size limit imposed by the regulation, and $13 \%$ thought that the size limit was $22 \mathrm{~mm}$ or less). About $61 \%$ of the harvesters claimed that their harvest rarely went above the $20 \mathrm{~kg}$ bag limit, while the remaining $39 \%$ admitted to harvest $20 \mathrm{~kg}$ or more most of the time. Oceanographic conditions were considered the main limiting factor to the amount harvested.

When asked about their perception of transgression occurring within the harvester population, $55 \%$ claimed that harvesting beyond the bag limit $(20 \mathrm{~kg})$ was frequent or very frequent, and $87 \%$ claimed that the imposed size limit was frequently or very frequently not fulfilled. For $58 \%$ of the harvesters, size limit was the management rule that was most difficult to fulfil. A very high percentage of the harvesters (82\%) agreed with the $20 \mathrm{~kg}$ per day bag limit. Among the harvesters who agreed with this measure, some claimed that the total amount allowed should depend on the existing stock, and that it could even drop to $15 \mathrm{~kg}$.

Most harvesters $(66 \%)$ disagreed with the size limit imposed, claiming that it should drop to 18-22 mm RC, because it is very difficult to fulfil this requirement due to a low abundance of large-sized individuals in the intertidal zone. Harvesters' opinions regarding the size (RC) of a set of 6 reference barnacles with different sizes and whether each of these barnacles would be exploited are shown in Figure 4. Barnacles C (20.1 mm) to F $(29.6 \mathrm{~mm})$ were considered good-sized barnacles (only F-sized barnacles were considered excellent). Most harvesters shared the opinion that barnacles with sizes D $(22 \mathrm{~mm})$ to $\mathrm{F}$ would be targeted during their harvest.

\section{RNB nature guards}

All nature guards interviewed participated in surveillance tasks at the RNB, and had been working there for 7 to 21 years. They all knew the regulation for barnacle harvesting at the RNB, and all stated that there was no specific surveillance plan for this activity. General sea and shore surveillance for all kind of activities in the RNB area is part of their normal tasks. Amounts and sizes of the harvested barnacles are rarely controlled by them and three out of five guards claimed that surveillance and control of the bag and size limits imposed by the regulation is difficult. They all agreed that harvesters do not follow the regulation, suggesting that there should be more effective ways to penalize transgressors.

Most of them stated that all kinds of transgressions to the barnacle harvesting regulation are frequent, and 

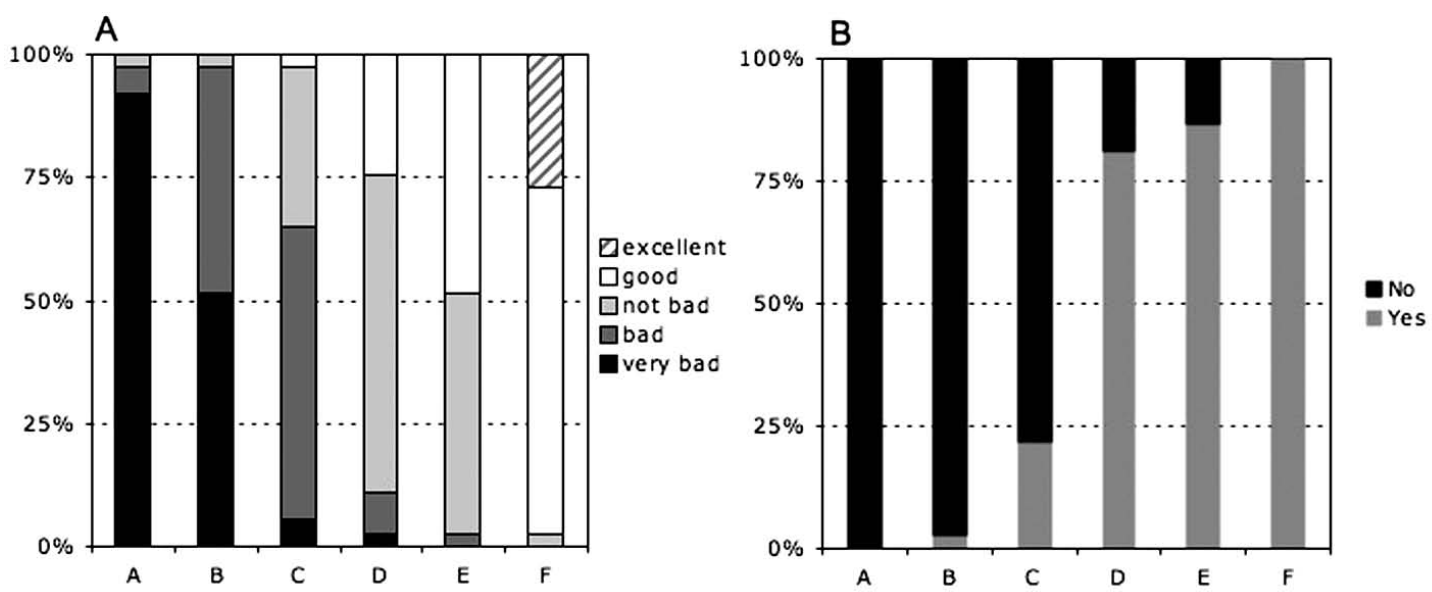

FIG. 4. - Fishery of $P$. pollicipes in the RNB: (A) relative opinion (very bad to excellent) of harvesters regarding the size of a set of 6 reference barnacles with different RC lengths (A-14 mm, B-17 mm, C-20.1 mm, D-22 mm, E-25.3 mm and F-29.6 mm) and (B) relative number of positive and negative answers to the question of whether the harvesters would collect barnacles with those sizes ( $\mathrm{n}=37$ harvesters).

they had all witnessed transgressions. They all shared the opinion that surveillance in sea and land control is insufficient or inexistent.

\section{DISCUSSION}

The results presented in this study show that the licensed harvesters are not following the bag- and sizelimit measures of the management plan for barnacle harvesting at the Berlengas Nature Reserve.

Although most of the time ( $75 \%$ of the observations) the catches per individual were less than or equal to the total amount allowed $(20 \mathrm{~kg})$, a certain number of men harvested far more than that (up to $36 \mathrm{~kg}$ or even more). The amounts captured per harvester/day in the RNB were in the same order of magnitude as those observed by Jesus (2006) in SW Portugal (14 to $24 \mathrm{~kg}$ per harvester/day) during a time when no management plan on barnacle harvesting was in place on this coast. Castro (2004) estimated that the sustainability of human exploitation of barnacles in SW Portugal could be at risk if high levels of exploitation continued. This is not the case of the RNB, where the sustainability of barnacle harvesting exploitation seems to be free of risk, as suggested by Jacinto et al. (2010).

One of the most successful cases of barnacle exploitation comes from Galicia, Spain (Molares and Freire, 2003). In this region, $P$. pollicipes exploitation is based on territorial user rights for fishing (TURFs) and is comanaged by local fishers' associations and the fisheries authorities, with the aim of incrementing profit while maintaining a sustainable activity. In order to maintain high commercial value, the allowed amounts per capita are more restrictive than in the RNB: from 4 to $10 \mathrm{~kg}$ per harvester per day (according to the exploitation plans for 2010 from various fisher's associations (www.pescadegalicia.com)). When comparing the RNB to Galicia, we must note that the maximum allowed harvest per capita in Galicia refers to what may be sold after sorting and not to what may be caught (as in the RNB). The total amount harvested in Galicia can be twice as much as the official reported sales (amount harvested after sorting), as was observed in one of the fishers' associations (Macho et al., 2008).

Our observations regarding the size of the barnacles harvested in the RNB in Autumn 2005 and 2006 suggest that the size limit imposed by the management plan was not always observed during this period. Only half of the sampled amounts were in agreement with the barnacle harvesting regulation (50\% of total biomass comprised individuals $\geq 25 \mathrm{~mm} \mathrm{RC}$ ). Differences regarding the relative contribution of different size classes to total biomass among the sampled amounts might be caused by several factors, including: 1 ) variable size structure of barnacle populations along the intertidal/shallow subtidal axis; 2) differential access to larger-sized animals depending on the harvesting technique used (low tide harvesting or free diving during high tide: free diving allows more time to choose the animals and to catch individuals from more difficult habitats like vertical walls or subtidal refuges); and 3) variable individual harvesting performance (less experienced men or elders tend to risk less and exploit barnacles higher in the intertidal).

Along the vertical dimension, larger individuals are more abundant in the low intertidal/shallow subtidal zone. This has been observed throughout its distributional range (Barnes, 1996; Cruz, 2000; Borja et al., 2006b; Cruz et al., 2010) and also in the RNB area (Cruz et al., 2008). Most of the exploited barnacles in the RNB (and at other harvesting sites) come from the low intertidal populations due to their higher quality for human consumption and higher commercial value (Cruz et al., 2008). However, these populations are not always accessible (due to tidal regime and wave climate), and some harvesters do not take the risk to exploit them and just collect smaller individuals from the higher intertidal zone.

Barnacle population size structure varies in time and space as a consequence of variable recruitment and 
growth patterns (Cruz et al., 2010). As our observations were made in autumn, further research is needed to assess the size structure of harvested barnacles in the RNB during the rest of the year.

Until 2009, along the Galician coast barnacle harvesting was directed towards individual specimens with $4 \mathrm{~cm}$ total length (at least $60 \%$ of the catch biomass had to comprise individuals longer than $4 \mathrm{~cm}$ ). In July 2009, the Galician legislation on this matter was changed. Now, the size limit is $15 \mathrm{~mm}$ diameter of the base of the capitulum (DBC) (at least 60\% of the catch biomass must consist of individuals larger than or equal to $15 \mathrm{~mm} \mathrm{DBC}$ ). For comparison purposes, on the basis of a strong linear relationship found between DCB and RC in barnacles collected in the RNB $(\mathrm{N}=1546 ; 4.5 \mathrm{~mm}<\mathrm{RC}<37.5 \mathrm{~mm})$, we estimated that a barnacle with $\mathrm{DBC}=15 \mathrm{~mm}$ refers to a barnacle with $21 \mathrm{~mm} \mathrm{RC} \mathrm{(D.} \mathrm{Jacinto,} \mathrm{unpublished} \mathrm{data).} \mathrm{Considering}$ size-limit rules, the Galician management regulation is less restrictive than the RNB one.

The answers to the enquiries given by the harvesters reveal that there is a strong regional and familiar tradition regarding barnacle harvesters working at the RNB. Despite the age difference between these men, most of them claim to have a large experience as barnacle harvesters, and that this is their main professional activity (although the great majority of them still have other sources of income). Although they are experienced harvesters and familiar with the management plan, there is a generalized opinion that the harvesters do not follow the regulation. Some of the reasons invoked for the infringement are related to lack of control and detachment of the regulation from reality.

All harvesters were aware of the bag limit, but not all seemed to know the precise size limit imposed by the regulation. Most of the harvesters claimed that their harvest rarely reaches the bag limit, while some admit to frequently harvest $20 \mathrm{~kg}$ or more. Oceanographic conditions are considered the main limiting factor to the amount harvested. For most of the harvesters, size limit is the most difficult rule to fulfil due to a low abundance of large-sized individuals in the intertidal zone, and most agree that this measure should be revised. Our observations suggest that, although difficult, it is not necessarily impossible to fulfil this size requirement because some of the harvesters working in the intertidal zone during low tide were able to. However, significant differences were found between the size structure of low and mid-shore barnacles, with larger-sized individuals being more abundant in the low shore (Cruz et al., 2008). Based on this study, it is impossible to fulfil the size limit rule if the exploitation is addressed to midshore barnacles. Growth of this species is highly variable and there are few studies about this (Cruz et al., 2010). Preliminary observations made in SW Portugal (Cruz, 2000) and in the RNB (Cruz et al., 2008) indicate that maximal size of a 1-year-old individual is $20-22 \mathrm{~mm}(\mathrm{RC})$. Barnacles are sexually mature with a RC $\geq 12.5 \mathrm{~mm}$ (Cruz and Araújo, 1999).
Although more studies are needed on the growth rate of $P$. pollicipes, based on the actual knowledge of its biology and on the opinion of barnacle harvesters, we believe that the management regulation in the RNB regarding the size limit could be altered. As surveillance and control of this activity are scarce (Jacinto et al., 2010), and since the results from the interviews with the harvesters show that a $22-\mathrm{mm}$-sized barnacle was considered "not bad" and a preferred target for most of the harvesters, we consider that lowering the size limit to $22 \mathrm{~mm}$ is a good compromise, which would enable harvesters to work within the legal limits, while maintaining a stock of reproductive active animals (and substrate for settlement) in the local barnacle population.

We recommend the maintenance of the bag limit rule and a reduction in the size limit regulation, and consider that more studies on the growth of this species should be carried out.

One of the key elements in the success of resource management and conservation is the control and monitoring of fishers' captures. Failure in this area has been described by Lauzier (1999a, b) as one of the main problems in the management of the gooseneck barnacle (P. polymerus) in Canada. The interviews with both harvesters and RNB nature guards suggest that lack of surveillance and control is a major problem in the RNB. In fact, the insufficient surveillance and control of the barnacle harvest by the RNB and fishing authorities has led to a situation in which harvesters are able to harvest with a minimal respect for the management plan. The limits they impose on their catches (bag and size limits) are self-oriented, and are driven by the empirical sense of the immediate gains associated with their effort.

Shore surveillance could be improved by developing a monitoring plan targeting this resource, including more intensive monitoring during low-spring-tide days and days of very calm seas, when harvesting pressure is higher (Jacinto et al., 2010). In Galicia, some fishers' organizations have their own surveillance services that collaborate with the government fishery inspection service, and this co-surveillance has effectively enforced individual harvesting limits (Molares and Freire, 2003). Recently, an association of $P$. pollicipes harvesters in the RNB was created. We recommend that the RNB, fishing authorities and this association collaborate in the future to implement a more effective surveillance plan. Such a plan would guarantee that licensed harvesters follow the management rules and provide a way to reduce illegal barnacle harvesting, which although not quantified is still present in this area (Jacinto et al., 2010).

We also recommend the definition of a single landing site at the port of Peniche. The inexistence of a formal landing site at the port of Peniche makes control of the amounts and sizes of the catches very difficult, since different boats tend to use different sites throughout the port. A formal landing site would make it easier 
to monitor amounts and individual sizes and to gather statistical data on this activity. It could also be used by the harvesters to sort their catches and prepare them for commercial distribution.

Models of co-management based on TURFs in shellfish exploitation in Galicia (Spain) have proved to be successful (e.g. Molares and Freire, 2003; Frangoudes et al., 2008) and could be seen as examples to follow not only in the RNB but also along the Portuguese coast wherever $P$. pollicipes exploitation is important and/or lacks a management plan.

\section{ACKNOWLEDGEMENTS}

We thank Dr. A. Teixeira (director of the RNB during this study) and the remaining RNB staff for the help and resources they provided for this project. We are grateful to the barnacle harvesters who kindly agreed to share their knowledge and opinions with us. We also thank three anonymous reviewers for commenting on an earlier version of the manuscript. This study was part of the project "The stalked barnacle (Pollicipes pollicipes) fishery and management at the Natural Reserve of Berlengas: patterns and impacts" (POCTI/ BIA-BDE/58206/2004) funded by the Fundação para a Ciência e Tecnologia (FCT).

\section{REFERENCES}

Bald, J., A. Borja and I. Muxika. - 2006. A system dynamics model for the management of the gooseneck barnacle (Pollicipes pollicipes) in the marine reserve of Gaztelugatxe (Northern Spain). Ecol. Model., 194: 306-315.

Barnes, M. - 1996. Pedunculate Cirripedes of the genus Pollicipes. Oceangr. Mar. Biol. Annu. Rev., 34: 303-394.

Borja, A., P. Liria, I. Muxika and J. Bald. - 2006a. Relationships between wave exposure and biomass of the goose barnacle (Pollicipes pollicipes, Gmelin, 1790) in the Gaztelugatxe Marine Reserve (Basque Country, northern Spain). ICES J. Mar. Sci., 63: 626-636.

Borja, A., I. Muxika and J. Bald. - 2006b. Protection of the goose barnacle Pollicipes pollicipes, Gmelin, 1790 population: the Gaztelugatxe Marine Reserve (Basque Country, northern
Spain). Sci. Mar., 70: 235-242.

Castro, J.J. - 2004. Predação humana no litoral rochoso alentejano: caracterização, impacte ecológico e conservação. $\mathrm{PhD}$ thesis, Universidade de Évora, pp. 367.

Cruz, T. - 2000. Biologia e ecologia do percebe, Pollicipes pollicipes (Gmelin, 1790), no litoral sudoeste português. $\mathrm{PhD}$ thesis, Universidade de Évora, pp. 306.

Cruz, T. and J. Araújo. - 1999. Reproductive patterns of Pollicipes pollicipes (Cirripedia: Scalpellomorpha) on the southwestern coast of Portugal. J. Crustac. Biol., 19: 260-267.

Cruz, T., J.J. Castro and S.J. Hawkins. - 2010. Recruitment, growth and population size structure of Pollicipes pollicipes in SW Portugal. J. Exp. Mar. Biol. Ecol., 392: 200-209.

Cruz, T., D. Jacinto, T. Silva, J.J. Castro, A. Marcelino, P. Maranhão and A. Teixeira - 2008. Exploração e Gestão do percebe (Pollicipes pollicipes) na Reserva Natural das Berlengas: padrões e impactes. Relatório final de execução científica (POCI) BIA-BDE/58206/2004). Universidade de Ëvora, pp. 48.

Frangoudes, K., B. Marugan-Pintos and J.J. Pascual-Fernandez. 2008. From open access to co-governance and conservation: The case of women shellfish collectors in Galicia (Spain). Mar. Policy, 32: 223-232.

Jacinto, D., T. Cruz, T. Silva and J.J. Castro. - 2010. Stalked barnacle (Pollicipes pollicipes) harvesting in the Berlengas Nature Reserve, Portugal: temporal variation and validation of logbook data. ICES J. Mar. Sci., 67: 19-25.

Jesus, D. - 2006. Gestão do percebe (Pollicipes pollicipes) no Parque Natural do Sudoeste Alentejano e Costa Vicentina, Teses em Gestão e Conservacão da Natureza, Gestão de Recursos Marinhos. Principia, Lisboa.

Lauzier, R.B. - 1999a. A review of the biology and fisheries of the goose barnacle (Pollicipes polymerus Sowerby, 1833). Canadian Stock Assessment Secretariat Research Document. Fisheries and Oceans Canada, 99/111: 30.

Lauzier, R.B. - 1999b. Framework for goose barnacle (Pollicipes polymerus Sowerby, 1833) fishery in waters off the west coast of Canada. Canadian Stock Assessment Secretariat Research Document. Fisheries and Oceans Canada, 99/198: 24.

Macho, G., J. Freire and J. Molares. - 2008. Development and prospective of the Galician TURF system (NW Spain) - The case of the gooseneck barnacle (Pollicipes pollicipes) fishery, The Seventh William R. and Lenore Mote International Symposium in Fisheries Ecology, 11-13 November 2008. Sarasota, Florida, USA.

Molares, J. and J. Freire. - 2003. Development and perspectives for community-based management of the goose barnacle (Pollicipes pollicipes) fisheries in Galicia (NW Spain). Fish. Res., 65: 485-492.

Scient. ed.: J.S. Troncoso.

Received December 10, 2009. Accepted November 17, 2010

Published online April 8, 2011. 